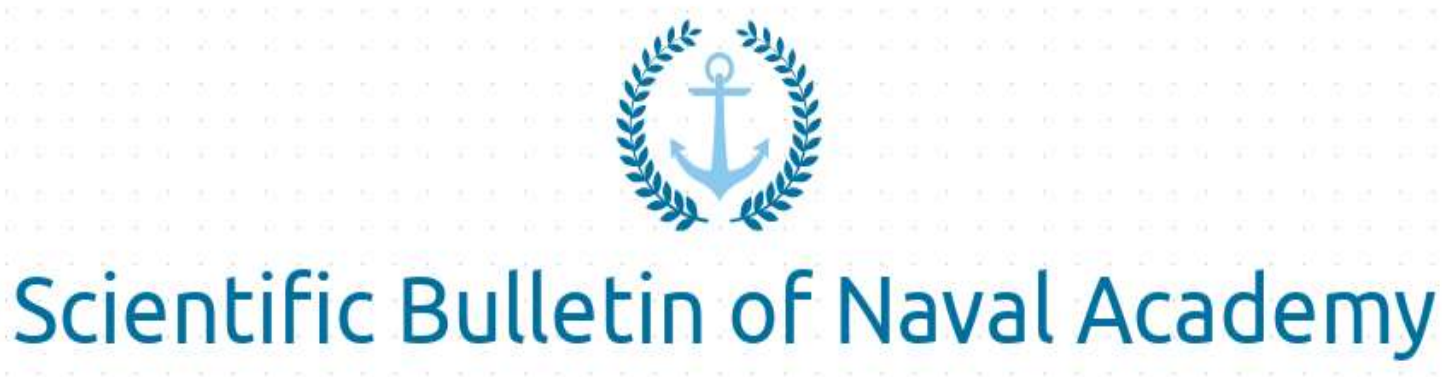

SBNA PAPER • OPEN ACCESS

Hydrodynamic Numerical Analysis of Intermediate and High-Speed Ships

To cite this article: K. Turgut Gürsel, Denizhan Özenen, Scientific Bulletin of Naval Academy, Vol. XXIII 2020, pg.146-157.

Available online at www.anmb.ro

ISSN: 2392-8956; ISSN-L: 1454-864X 


\title{
Hydrodynamic Numerical Analysis of Intermediate and High-Speed Ships
}

\author{
K. Turgut Gürsel and Denizhan Özenen \\ "Dokuz Eylül University -Institute of Marine Sciences and Technology - Department \\ of Naval Architect - Haydar Aliyev Bulvarı, No: 32, İnciraltı - 35330 İzmir" \\ Corresponding author: turgut.gursel@deu.edu.tr
}

\begin{abstract}
Due to rising energy costs and increasing concern about environmental pollution, it has become very important to precisely estimate the hydrodynamic resistance forces of ship forms in order to equip the ships with engines with optimum power and to increase their cruising radius considerably. To limit the scope of the highly expensive towing tank experiments and to estimate the resistance of a ship form in a wide speed range and under each loading and sea condition, it has become a practical necessity to approximately achieve those results of the resistance forces with computational fluid dynamics (CFD) analyses.

The aim of this study is to compare the resistance results of ship models having different forms, which were obtained by performing CFD analysis by using ANSYS Fluent 16.0 software, with those of the towing tank resistance tests of these vessels. Further, considering these results obtained, a three-dimensional model of a boat form was created using the Rhinoceros software whose towing tank test results do not exist before, and resistance estimations of the created form were made using CFD analyses in ANSYS Fluent 16.0 software. In this way, it will be possible to obtain realistic numerical resistance estimation values of a ship form or a newly designed boat model, which has no previous towing tank test results, by performing CFD analyses under each loading and sea condition in a very wide speed range.
\end{abstract}

\section{Introduction}

Due to the energy problems having emerged in the world since the second half of the twentieth century, and thus rising fuel prices, the estimation of the hydrodynamic resistance forces of the ships has become even more important when designing the vessel forms. Therefore, the aim of a ship design carried out in this respect is to enable the ship and/or boat to cruise faster with minimum fuel consumption. In this process, it is of great importance to investigate the hull resistance by analysing the behaviour of the hull form in the water using various methods. By estimating the resistance values of the hull form at different speeds, more detailed and precise information about the design and structure of the form can be obtained. Thus, by making necessary improvements on the form, it is possible to ensure that the ship cruises with minimum resistance and optimum propulsion efficiency. In addition, hull form is another important design parameter that has a great impact on the transverse stability of the ship.

Measuring total resistance values of a ship model in towing tank tests and developing hull forms based on these measurements is a valid basic method, because this method is the technique that can give 
the closest results in the resistance forces of a hull form. However, this method also has disadvantages: The most important of which is that it is time consuming and very costly. In this method, it is necessary to reflect all the details of the full scale hull to the model, therefore it is of great importance to be able to make detailed manufacturing of the model and to be able to conduct towing tank tests at a demanded speed range. In addition, due to the length of the towing tank and the characteristics of the towing vehicle, high cruising speeds may need to be limited in these tank tests.

Due to the development of Computational Fluid Dynamics (CFD) method, it has become possible to determine the factors that directly affect the hydrodynamics, performance, manoeuvrability and stability of a ship in the design processes of her hull form. Within the scope of this method, the basic equations of fluid mechanics are solved by using certain mathematical methods and various algorithms, and the speed and pressure of the flow around the hulls and the resistance forces to which ship forms are exposed, are determined. By comparing the data obtained through CFD analyses with the physical towing tank test results of the models, it is possible to obtain reliable data and to perform more detailed and complex numerical analyses based on these data.

The aim of this study is to obtain resistance values of three different ship forms by using the CFD analysis method. The resistance values of the models INSEAN 2340 and Harmen Oldendorff obtained as a result of the CFD analyses using ANSYS Fluent software will be verified by their test results comparatively, which have been tested before. In the last step, the resistance values of the A.P. model having a different form were estimated, which were obtained in a wide range of speeds by the CFD analysis method.

After verifying CFD analysis results of the models by their existent towing tank test ones, the CFD simulations of these models with appendages such as rudder, shaft, bilge keel, etc. will be repeated, and additionally, it is possible to perform CFD simulations for speeds that cannot be achieved in the towing tank tests. Therefore, the aim is to conduct simulations on numerical models of the ships by CFD analysis method after selecting an appropriate turbulence models under different loading and sea conditions within a wide range of speeds, without any need for physical tank tests and other approximate resistance estimation methods required in design stages of ships and boats.

\section{Materials and Method}

\subsection{Applying Navier Stokes Equations and Turbulence Model in CFD Analyses}

In fluid mechanics, the equations of motion of Newtonian incompressible fluids are expressed with the Navier Stokes equations, and changes in both velocity and pressure fields can be calculated for a given geometry and boundary conditions. The conservative Navier Stokes transport equation shown in Equation 1 is a non-linear, non-continuous second order partial differential equation.

$$
\rho\left[\frac{\partial \vec{V}}{\partial t}+(\vec{V} \cdot \vec{\nabla}) \vec{V}\right]=-\vec{\nabla} P+\rho \vec{g}+\mu \nabla^{2} \vec{V}
$$

If, using a turbulence model in CFD calculations, all turbulent eddies are modelled, Reynoldsaveraged flow properties are calculated. Thus, the Navier-Stokes equations are replaced by a more specific equations called the Reynolds-Averaged Navier-Stokes (RANS) equations. Equation 2 used for a steady, incompressible and turbulent flow is called the steady RANS equation. Since Equation 3 functions as the viscous stress tensor $\tau_{i j}$, it is known as the specific Reynolds stress tensor.

$$
(\overrightarrow{\mathrm{V}} \cdot \vec{\nabla}) \overrightarrow{\mathrm{V}}=-\frac{1}{\rho} \vec{\nabla} P^{\prime}+u \nabla^{2} \overrightarrow{\mathrm{V}}+\vec{\nabla} \cdot\left(\tau_{i j, \text { türbülans }}\right)
$$




$$
\tau_{i j, t \text { ürbülans }}=-\left(\begin{array}{lll}
\overline{\frac{u^{\prime 2}}{u^{\prime} v^{\prime}}} & \overline{u^{\prime} v^{\prime}} & \overline{u^{\prime} w^{\prime}} \\
\overline{u^{\prime} w^{\prime}} & \frac{\overline{v^{\prime} w^{\prime}}}{v^{\prime} w^{\prime}} & \overline{w^{\prime 2}}
\end{array}\right)
$$

In computational fluid dynamics analyses of those ship models treated in the section below, the turbulence model "Shear Stress Transport $k-\omega$ (SST $k-\omega)$ " of the software ANSYS/FLUENT V16.0 was applied [1]. The reason for the selection of this turbulence modelling is that it includes a blending function activating the standard $k-\omega$ model in the near-wall region and, however, the transformed $k-\varepsilon$ model in the far-field zones $[2,3]$. Further, since SST $k-\omega$ algorithm contains a modified turbulent viscosity formulation to calculate the transport effects of the principal turbulent shear stress, it generally gives accurate prediction of the onset and the size of the flow separation under adverse pressure gradients on a rigid hull. In the two equations used in the SST $k-\omega$ turbulence model, kinetic energy and convection are expressed in Equation 4 and 5, respectively [1,3]:

$$
\begin{gathered}
\frac{\partial}{\partial t}(\rho k)+\frac{\partial}{\partial x_{i}}\left(\rho k u_{i}\right)=\frac{\partial}{\partial x_{j}}\left(\Gamma_{k} \frac{\partial k}{\partial x_{j}}\right)+G_{k}-Y_{k}+S_{k} \\
\frac{\partial}{\partial t}(\rho \omega)+\frac{\partial}{\partial x_{i}}\left(\rho \omega u_{i}\right)=\frac{\partial}{\partial x_{j}}\left(\Gamma_{\omega} \frac{\partial \omega}{\partial x_{j}}\right)+G_{\omega}-Y_{\omega}+D_{\omega}+S_{\omega}
\end{gathered}
$$

\subsection{CFD Analysis Processes of the Models}

Towing tank test results of the ship models INSEAN 2340 and Harmen Oldendorff examined in this study are available, and there are no test results for the third ship model A.P. The model INSEAN 2340 is a $1 / 24.824$ scale model of the DTMB 5415 warship and has a special bulb-like geometry in the bow which enables the placement of the sonar device as shown in Figure 1. The 1/80 scale model of the dry cargo ship Harmen Oldendorff has a different geometric form as shown in Figure 2. The quality of the three-dimensional geometric models of the three ships selected is extremely important, because geometries must be converted into a solid model for CFD analyses perfectly, and then meshing of the solid models must be conducted carefully to have high quality in the mesh structure. Further in CFD analyses, it is extremely important to select the boundary conditions and flow parameters assigned to all models within appropriate intervals, because these values affect all results that will come out at the end of the analyses and enable the results obtained to be compared with the test results.

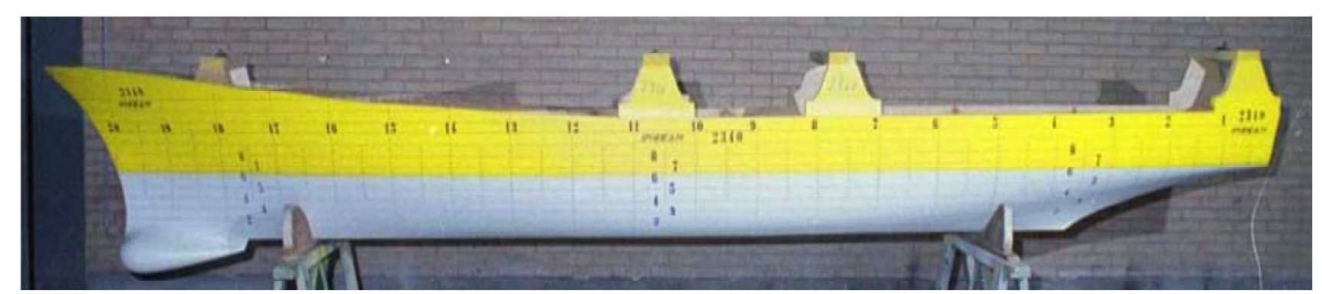

Figure 1. Ship model INSEAN 2340 [4] 


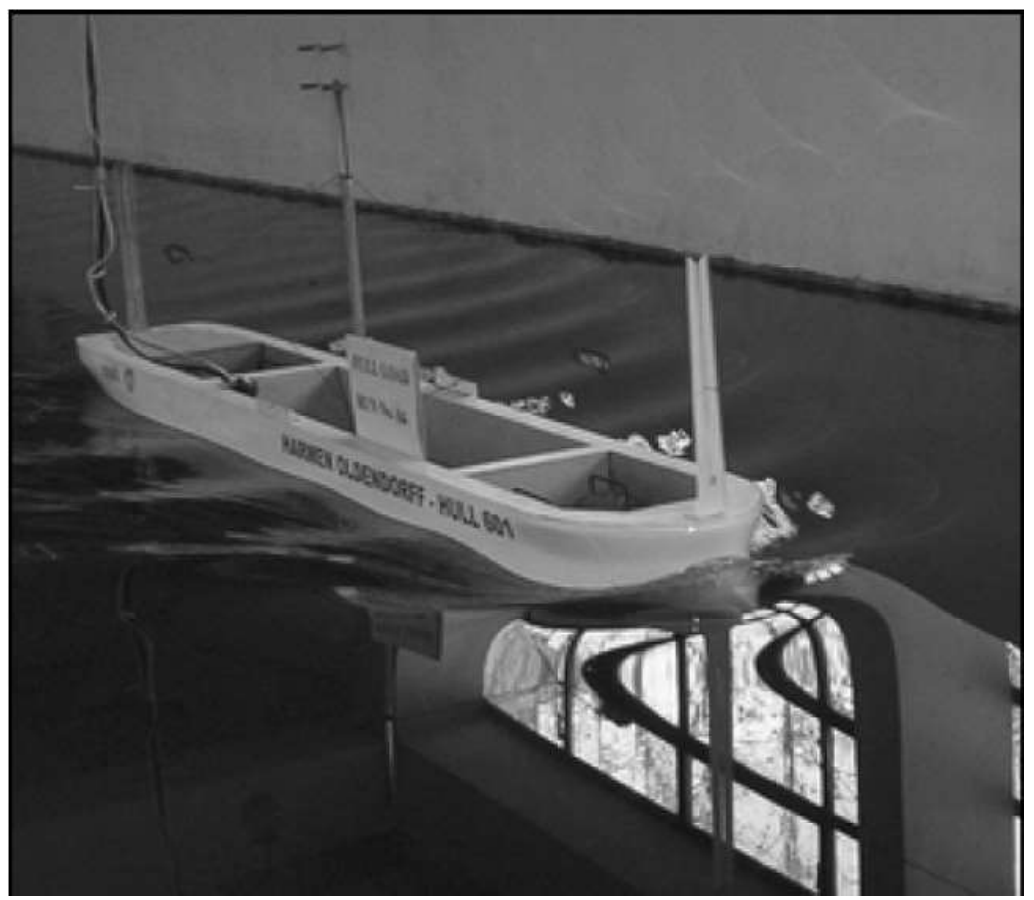

Figure 2. Ship model Harmen Oldendorff [5]

\subsection{Preparation of Geometries and Mesh Structures of the Models}

First, through the Rhinoceros software, the geometries of the three-dimensional ship models INSEAN 2340, Harmen Oldendorff and A.P. were prepared and transferred into ANSYS Fluent Design Modeller software. After the hull forms of all models were improved, the meshing of the models was started (Figure 3-5).

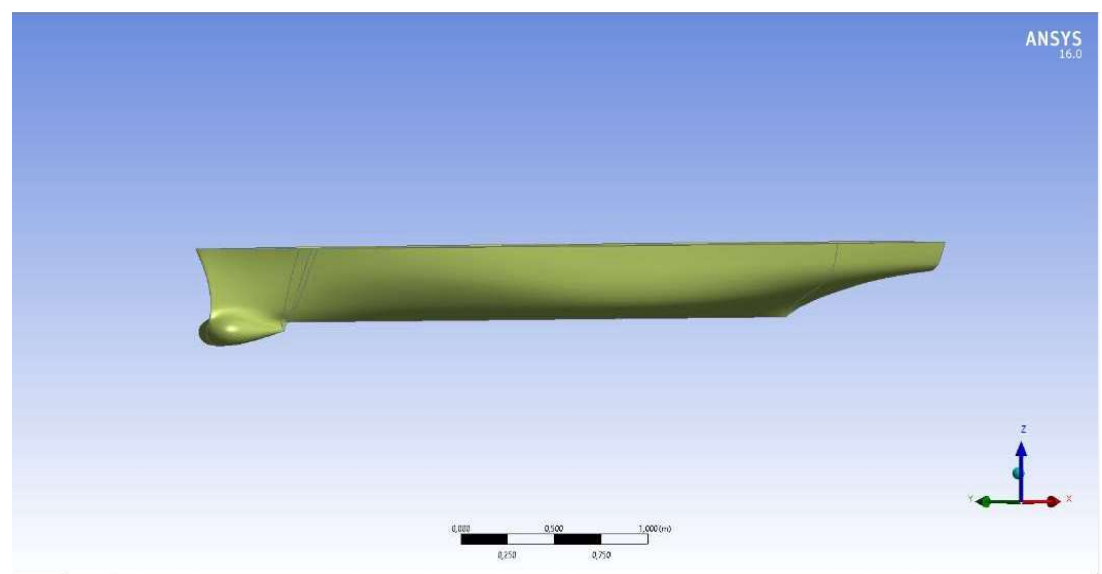

Figure 3. Three-dimensional hull model of INSEAN 2340 


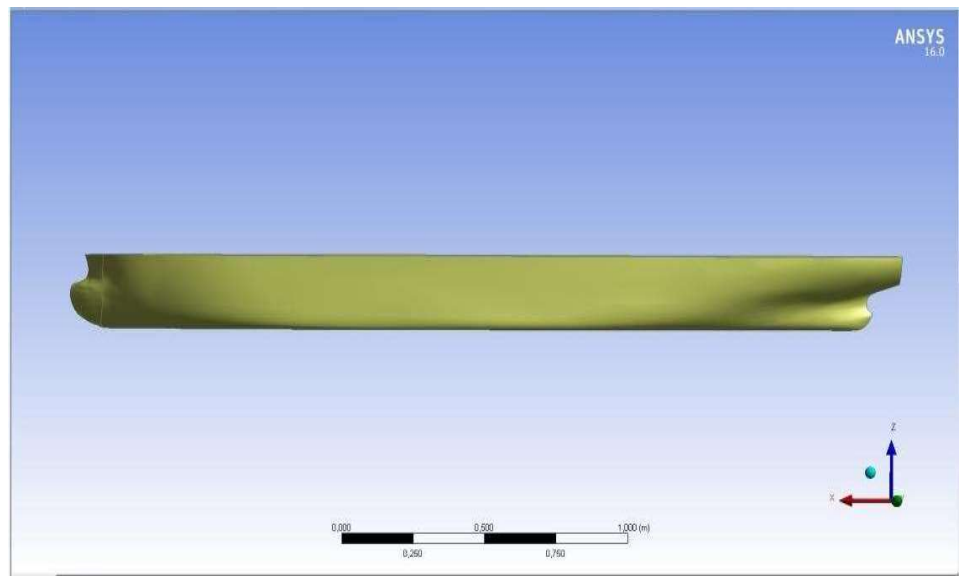

Figure 4. Three-dimensional hull model of Hermann Oldendorf

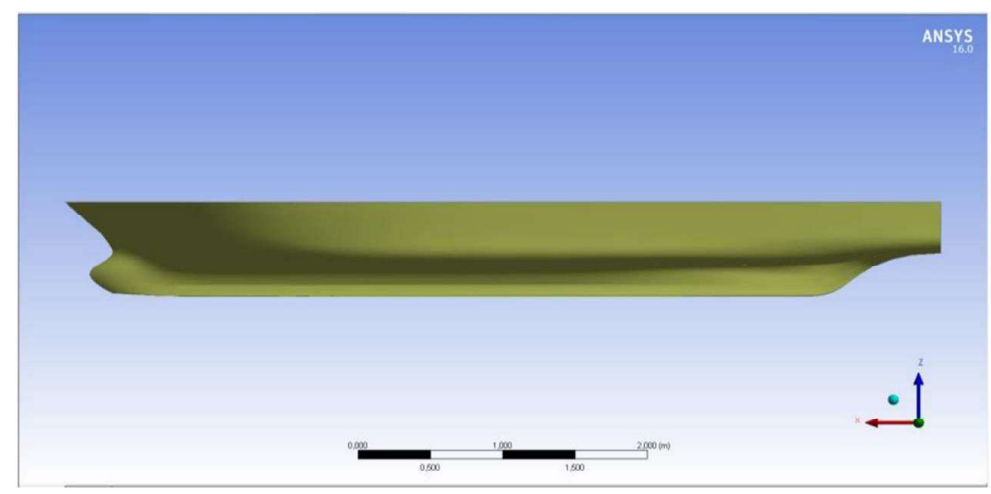

Figure 5. Three-dimensional hull model of A.P.

Failures made in numerical analyses originate generally from the mesh structures and/or turbulence models used, which can be selected inappropriately in applications. In this study, a mesh structure with tetrahedral elements was selected, which is most suitable for the curvilinear surfaces and narrow angle edges of the ship geometries and is further preferred for complex geometries. Indeed, increasing the number of finite volume elements in a geometry will increase the precision of the analysis result. However, the excessive increase in the number of these elements may cause a longer duration of the analysis and even its divergence. Here, the mesh structures of the models were corrected, until an optimal quality meshing of the studied models was obtained. During the implementation of the meshing, it has been ensured that the "orthogonal quality" ratio does not fall below 0.20 , which is the basic criterion.

In the analyses, it was considered that the $\mathrm{y}^{+}$values called wall function are low. Since the flow around the bulbous bow of the DTMB 5415 warship immediately turned from laminar to turbulent flow due to the sonar system placed at this bulbous bow, the wall function was determined to be $\mathrm{y}^{+}=45.9$. In the following stage, the sonar volume was approached to zero, and the value of the wall function was reached to be $y^{+}=2.63$ as shown in Figure 6 and Table 1 .

After applying the first mesh structure to the model form of Herman Oldendorff, the highest $\mathrm{y}^{+}$value of 27.8 was obtained. In the last stage, using finer mesh structure as shown in Figure 7, the highest $\mathrm{y}^{+}$ value was reduced up to 6.05 as given in Figure 8, and it was determined that the wall function yielded $\mathrm{y}^{+}<5.5$ except for the lower part of the stern shoulder, which is absolutely acceptable. 


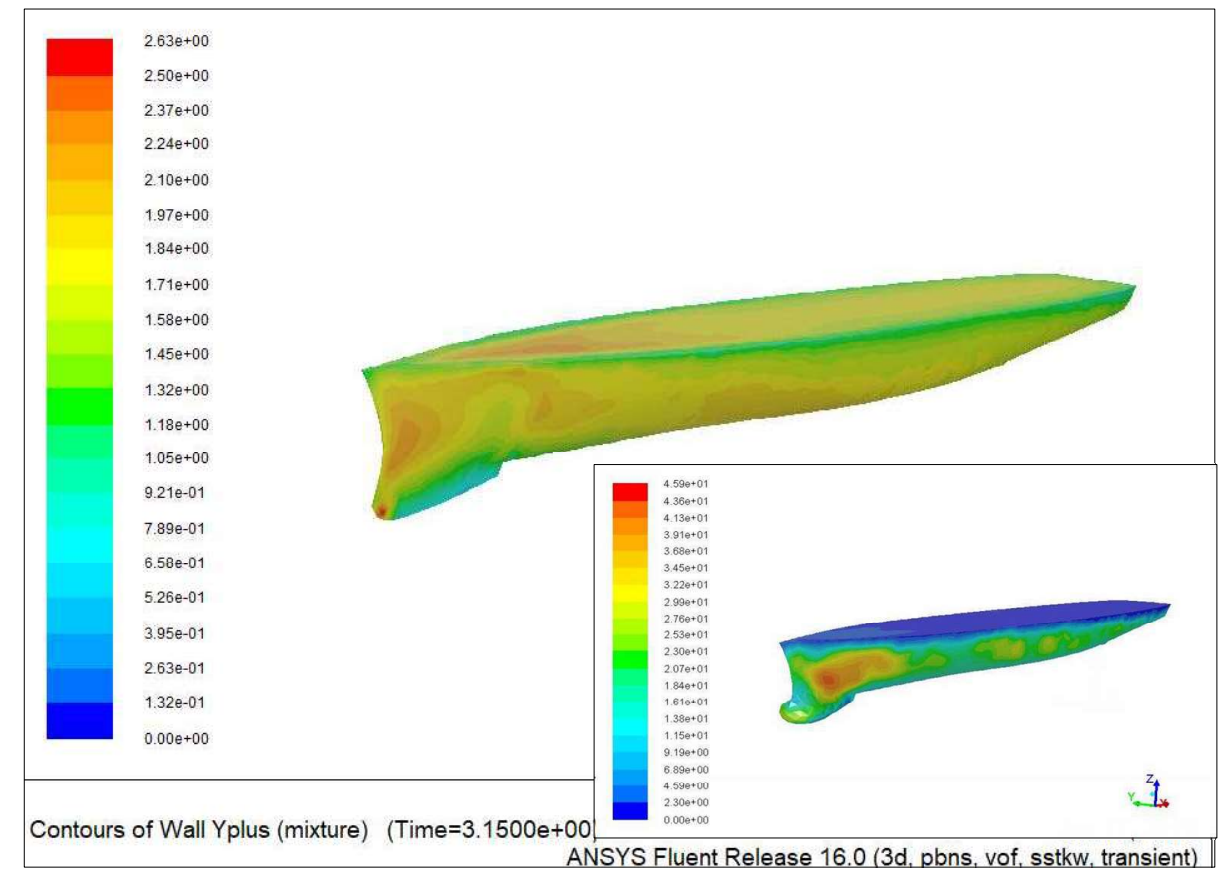

Figure 6. $\mathrm{y}^{+}$Values of the model form INSEAN 2340

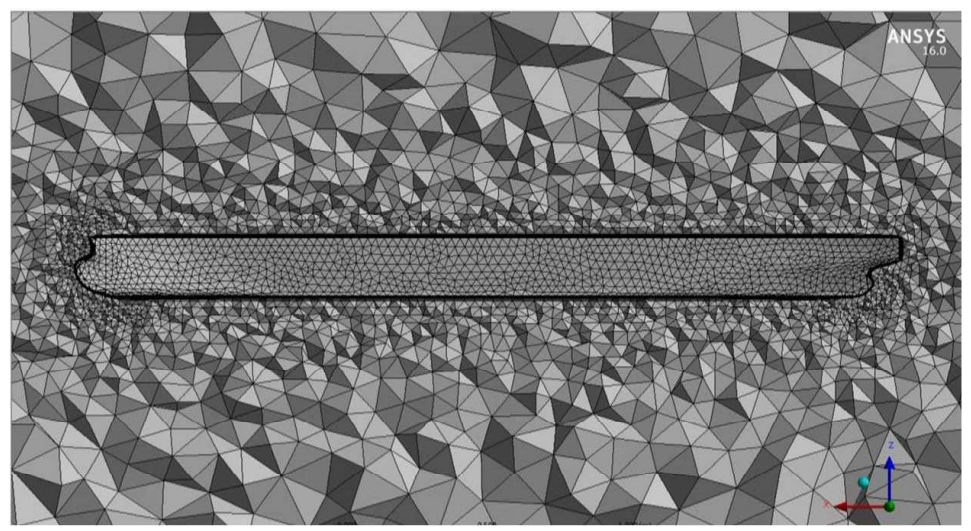

Figure 7. Improvement of the mesh structure in the boundary layer of the model Herman Oldendorff

After applying the first mesh structure to the model form of the boat A.P., the highest $\mathrm{y}^{+}$value of 81.4 was obtained, and then, the $\mathrm{y}^{+}$value was reduced up to 32.9 by using finer meshing in the following step. As both analyses were examined, it was found that the $\mathrm{y}^{+}$value was relatively high, especially at the lower part of the head shoulder. In the next stage, to see the range of the change of the $y^{+}$value, the bulb volume of the model form A.P. was approximated closer to zero, and then the model form was redrawn. As a result, the $\mathrm{y}^{+}$value of the model with the new head form and finer mesh structure was reduced up to 9.68 as shown in Figure 9. Maximum $\mathrm{y}^{+}$values obtained in this study on all ship model forms are given in Table 1 completely. 


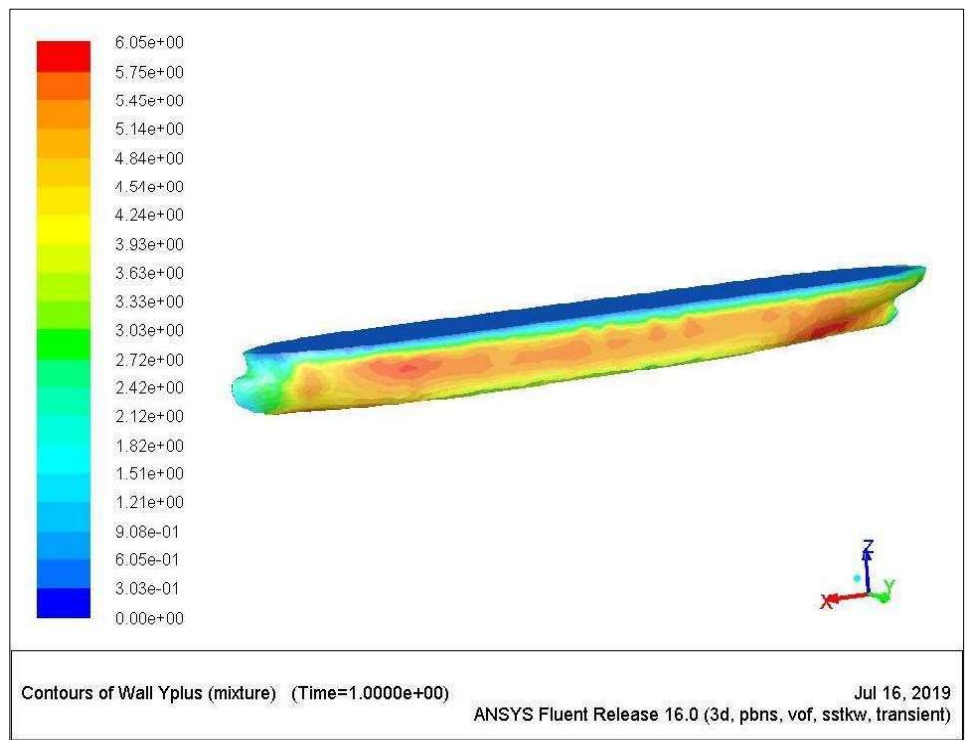

Figure 8. The $\mathrm{y}^{+}$values of the model form Herman Oldendorff with finer mesh structure

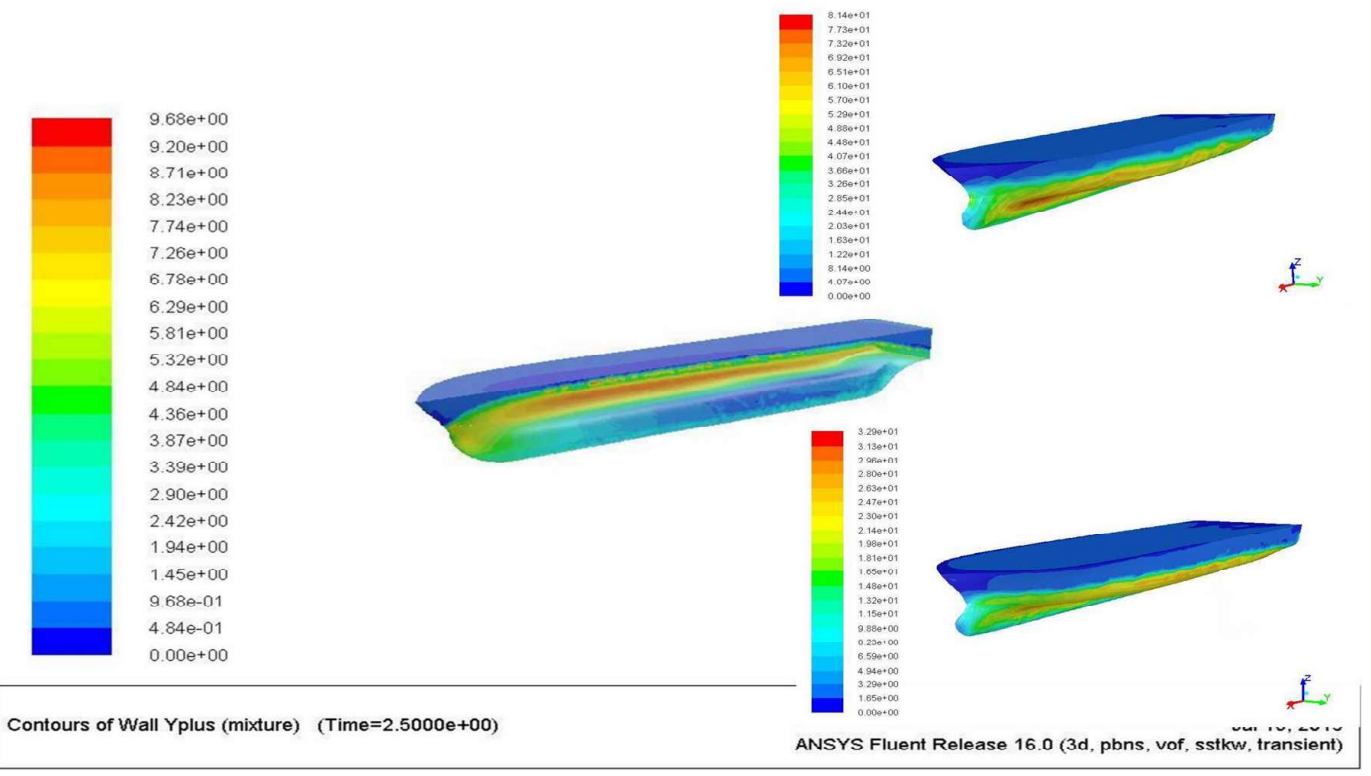

Figure 9. The $\mathrm{y}^{+}$distribution of the model A.P. with the new head form and finer mesh structure 
Table 1. The $\mathrm{y}^{+}$values of all model forms obtained with the new head form and finer mesh structure

\begin{tabular}{cccc}
\hline $\mathbf{y}^{+}$values in different cases & $\begin{array}{c}\text { INSEAN } \\
\mathbf{2 3 4 0}\end{array}$ & $\begin{array}{c}\text { Herman } \\
\text { Oldendorff }\end{array}$ & A.P. \\
\hline $\mathbf{y}^{+}:$Basic case & 60.4 & 27.8 & 81.4 \\
$\mathrm{y}^{+}:$Case I; Finer mesh structure & 45.9 & 6.05 & 32.9 \\
\hline $\mathbf{y}^{+}:$Case II; New head form & $\mathbf{2 . 6 3}$ & - & $\mathbf{9 . 6 8}$ \\
\hline
\end{tabular}

\subsection{Determination of Conditions of the Models in CFD Analyses}

Due to the presence of air and water separated from the free water surface as different environments investigated in this study, the multi-phase simulation technique was used in the analyses. Selection of the parameters and analysis inputs applied in CFD simulations were conducted in all models as a standard, and velocity changes in normal and tangential directions, wall functions, pressure contours and turbulence magnitudes obtained were examined depending on the turbulence models used. The surfaces of the input and output required in all models are shown in different colours as given in Figure 10 , and these colours are automatically assigned by the system so that "blue", "red" and "yellow" mean input, output and symmetry conditions, respectively.

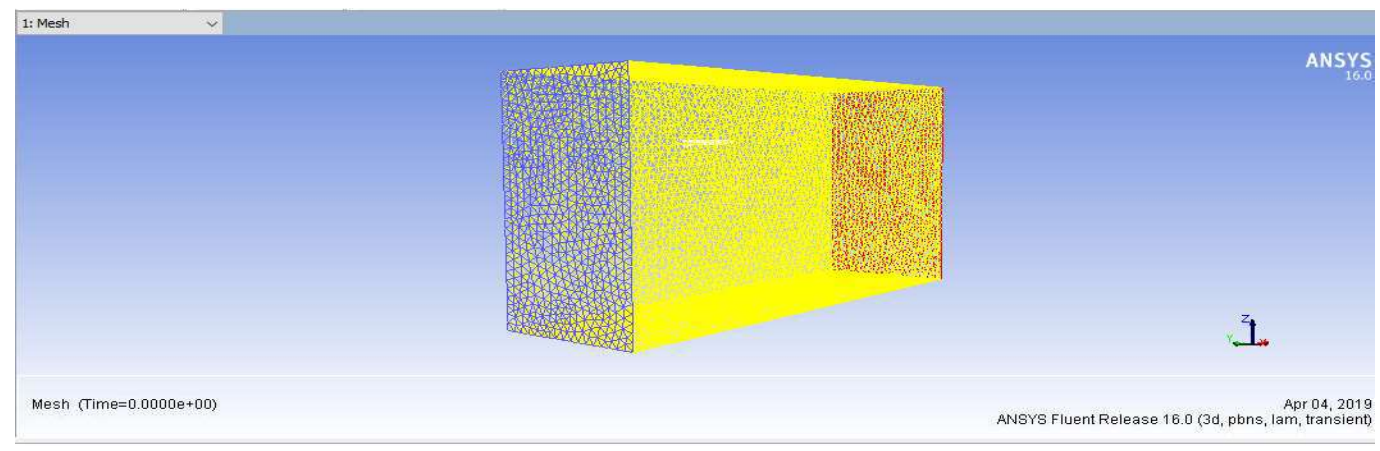

Figure 10. Establishing the analysis conditions

\section{Results of CFD Analyses of Ship Models}

\subsection{CFD Analysis of the Model INSEAN 2340}

The warship DTMB 5415 belonging to the United States navy was transformed into a $1 / 24.824$ scale model named INSEAN 2340 through Rhinoceros software. After this model was transferred into ANSYS Space Claim, a solid model required for CFD analyses was created. Then, the necessary mesh structure of the solid model was generated. After checking the quality of the meshing, the model was transferred into ANSYS Fluent software (Table 2). 
Table 2. Main Dimensions of the Warship DTMB 5415 and the model INSEAN 2340 [4]

\begin{tabular}{llccc}
\hline Descriptions & \multicolumn{2}{c}{ Symbols } & $\begin{array}{c}\text { Main Dimensions of } \\
\text { Ships }\end{array}$ & $\begin{array}{c}\text { Main Dimensions of } \\
\text { Models }\end{array}$ \\
\hline Length of waterline & $\mathrm{L}_{\mathrm{WL}}$ & {$[\mathrm{m}]$} & 142.0 & 5.720 \\
Length between perpendicular & $\mathrm{L}_{\mathrm{PP}}$ & {$[\mathrm{m}]$} & 142.0 & 5.720 \\
Beam & $\mathrm{B}$ & {$[\mathrm{m}]$} & 18.9 & 0.76 \\
Draft & $\mathrm{T}$ & {$[\mathrm{m}]$} & 6.16 & 0.248 \\
Displacement volume & $\nabla$ & {$\left[\mathrm{m}^{3}\right]$} & 8425.4 & 0.549 \\
Wetted surface & $\mathrm{S}_{\mathrm{W}}$ & {$\left[\mathrm{m}^{2}\right]$} & 2949.5 & 4.786 \\
\hline Displacement tonnage & $\boldsymbol{\Delta}$ & {$[\mathrm{t}]$} & $\mathbf{8 6 3 6 . 0}$ & $\mathbf{0 . 5 4 9}$ \\
\hline
\end{tabular}

The towing tank test results of the model INSEAN 2340 were published by Olivieri et al. [4]. In this study, in the CFD analyses of the model INSEAN 2340, total resistance values for 11 speeds between $0.371 \mathrm{~m} / \mathrm{s}$ and $3.371 \mathrm{~m} / \mathrm{s}$ defined in the towing tank test of the model, were obtained as close to the test results as shown in Figure 11.

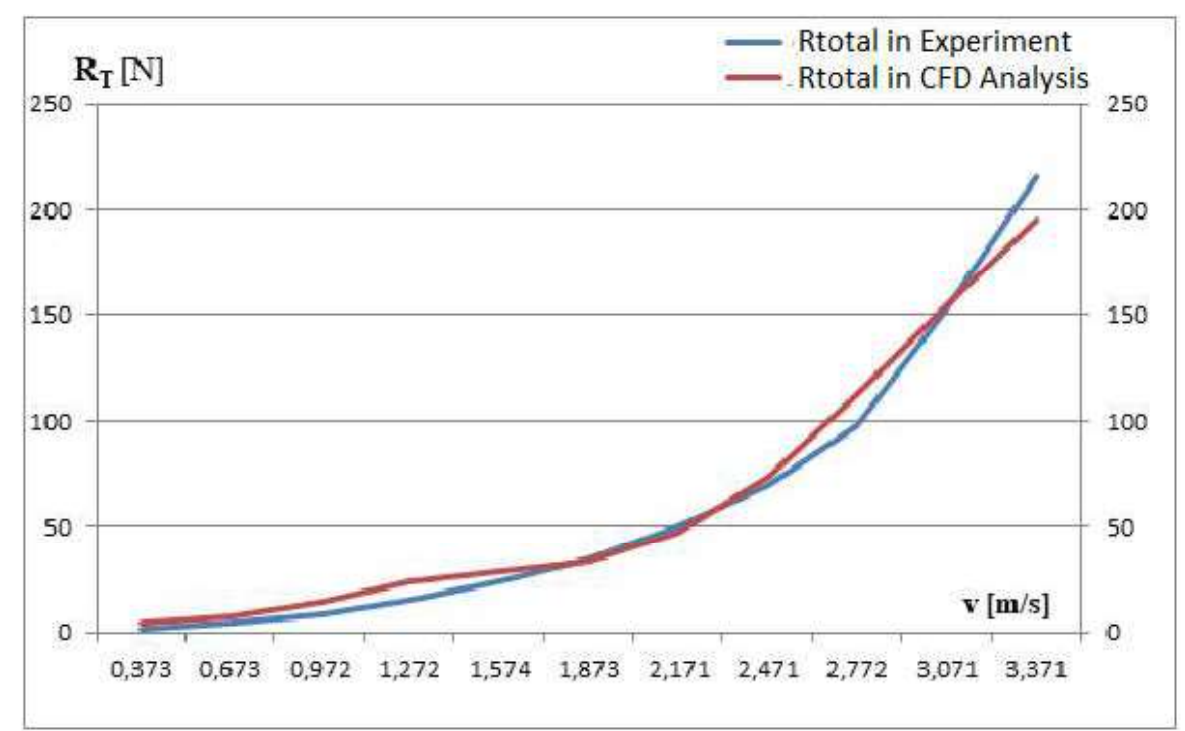

Figure 11. Results of the tank test and CFD analysis of the model INSEAN 2340

\subsection{CFD Analysis of the Model Herman Oldendorff}

In this study, the necessary corrections were made on the geometry of the $1 / 80$ scale geometric model of the cargo ship Harmen Oldendorff by transferring three-dimensional model data into Rhinoceros software, which is required for CFD analyses. The model was then transferred into ANSYS Space Calim and necessary improvements were performed on the solid model before of the CFD analyses. In the following stage, after a mesh structure was created, it was re-checked for the analysis. Finally, the model obtained was transferred into ANSYS Fluent software (Table 3). 
Table 3. Main Dimensions of the ship Herman Oldendorff and her model [5]

\begin{tabular}{llccc}
\hline Descriptions & Symbols & $\begin{array}{c}\text { Main Dimensions of } \\
\text { Ships }\end{array}$ & $\begin{array}{c}\text { Main Dimensions of } \\
\text { Models }\end{array}$ \\
\hline Length of waterline & $\mathrm{L}_{\mathrm{WL}}$ & {$[\mathrm{m}]$} & 220.915 & 2.761 \\
Length between perpendicular & $\mathrm{L}_{\mathrm{PP}}$ & {$[\mathrm{m}]$} & 217.30 & 2.716 \\
Beam & $\mathrm{B}$ & {$[\mathrm{m}]$} & 32.20 & 0.403 \\
Draft & $\mathrm{T}_{\mathrm{m}}$ & {$[\mathrm{m}]$} & 13.830 & 0.173 \\
Draft (Forward) & $\mathrm{T}_{\mathrm{f}}$ & {$[\mathrm{m}]$} & 13.830 & 0.173 \\
Draft (Stern) & $\mathrm{T}_{\mathrm{a}}$ & {$[\mathrm{m}]$} & 13.830 & 0.173 \\
Longitudinal Centre of Buoyancy & $\mathrm{LCB}$ & {$[\mathrm{m}]$} & 114.081 & 1.426 \\
Wetted surface & $\mathrm{S}_{\mathrm{W}}$ & {$\left[\mathrm{m}^{2}\right]$} & 11762.40 & 1.838 \\
\hline Displacement volume & $\boldsymbol{\nabla}$ & {$\left[\mathrm{m}^{3}\right]$} & $\mathbf{8 2 6 2 6 . 0}$ & $\mathbf{0 . 1 6 1}$ \\
\hline
\end{tabular}

In this context, the results obtained from the CFD analysis of the model Harmen Oldenorff at different speeds are given in Figure 12 in comparison with the tank test results, and it has been observed that the results obtained are very close to test ones.

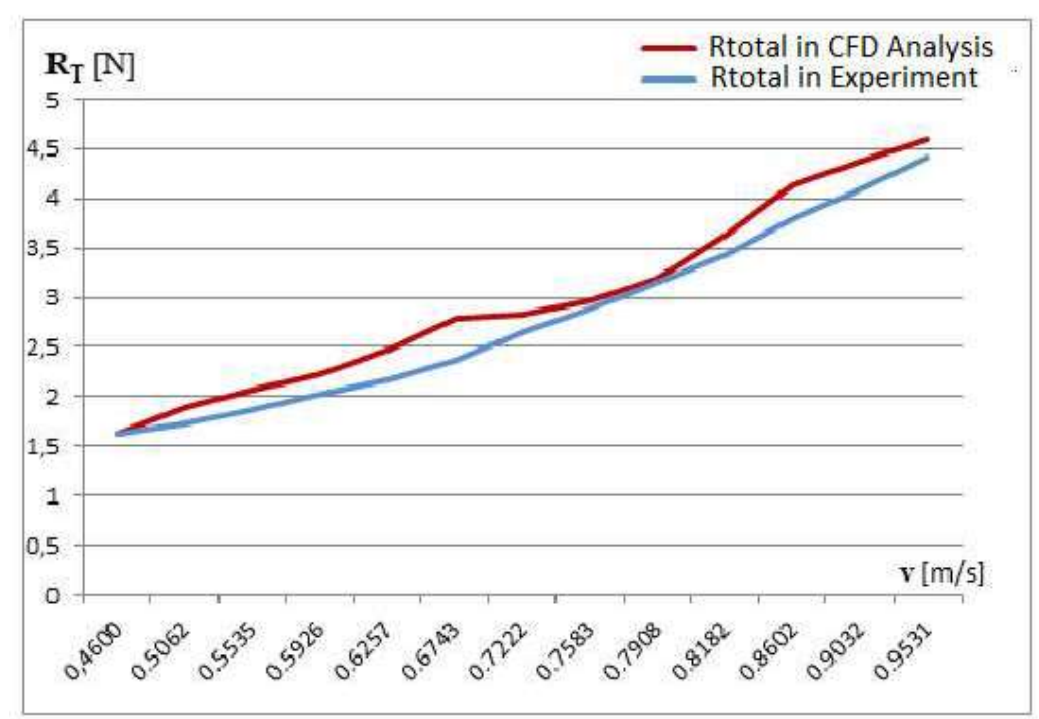

Figure 12. Results of the tank test and CFD analysis of the model Harmen Oldendorff

\subsection{CFD Analysis of the Model A.P.}

The ship A.P. examined in this section has been designed as a fishing boat and has been constructed with a high freeboard considering the severe operating conditions. First, a three-dimensional solid model of the boat A.P. with a scale of $1 / 24.824$ of which tank test results are inexistant, was created using the Rhinoceros software by means of the offset table of this ship (Fig. 13, Table 4). In the second stage, the necessary final improvements were made on the geometry of the three-dimensional model after transferring the data into ANSYS Fluent software. Further, the mesh structure required for CFD analyses was created, and after no more failures were detected in the mesh structure, the model was ready for the analyses. In the last stage, the resistance values of the model at different speeds were estimated in the CFD analyses as shown in Figure 14. 
Thanks to the CFD methods providing an important support solution for experimental studies in terms of time and cost, the CFD analysis method with the same turbulence model and similar mesh structure technique was applied to the boat model A.P. without any towing tank test results. It is seen, that the boat A.P. designed as a fishing vessel shows an appropriate increase in the resistance curve at low speeds $(\mathrm{v}=4-6 \mathrm{~m} / \mathrm{s})$, but the resistance values grow very sharply, when, especially after $\mathrm{v}=8 \mathrm{~m} / \mathrm{s}$, high speeds are reached. For this reason, it is thought that the boat is designed for the speed range of $\mathrm{V}_{\text {Service }}=12-14 \mathrm{kn}$, since high increases in fuel cost are expected as the boat reaches high speeds.

Table 4. Main Dimensions of the ship A.P. and her model

\begin{tabular}{llcc}
\hline Descriptions & \multicolumn{1}{c}{$\begin{array}{c}\text { Symbols } \\
{[\mathrm{m}]}\end{array}$} & $\begin{array}{c}\text { Main Dimensions of } \\
\text { Ships }\end{array}$ & $\begin{array}{c}\text { Main Dimensions of } \\
\text { Models }\end{array}$ \\
\hline Length of waterline & $\mathrm{L}_{\mathrm{WL}}$ & 31.00 & 6.20 \\
Length between perpendicular & $\mathrm{L}_{\mathrm{PP}}$ & 26.50 & 5.30 \\
Beam (Mold) & $\mathrm{B}_{\text {Mold }}$ & 7.66 & 1.532 \\
Beam (Deck) & $\mathrm{B}_{\text {Deck }}$ & 7.46 & 1.492 \\
Draft & $\mathrm{T}$ & 2.00 & 0.40 \\
Depth & $\mathrm{D}$ & 2.50 & 0.50 \\
\hline
\end{tabular}

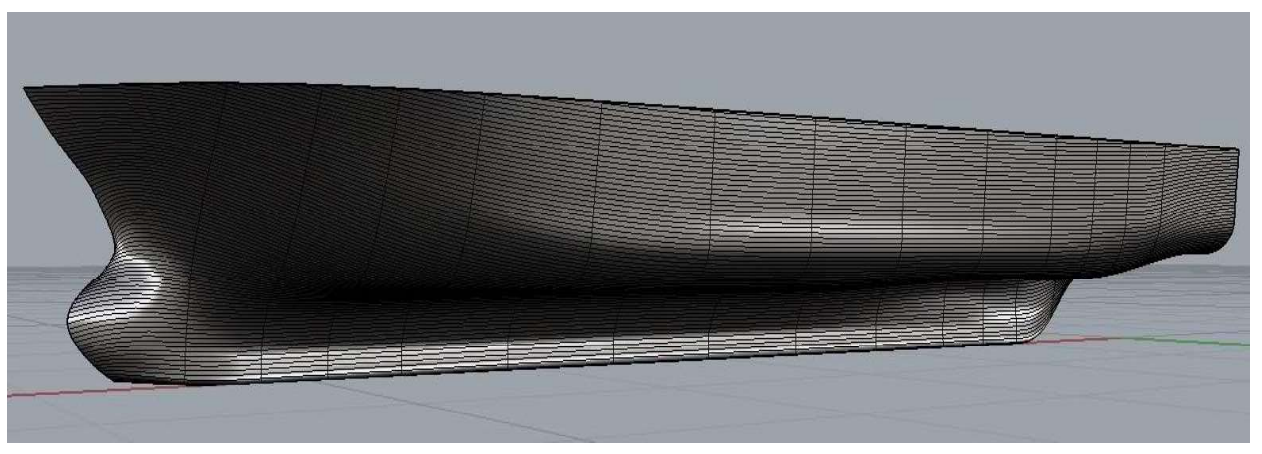

Figure 13. Solid model of the ship A.P.

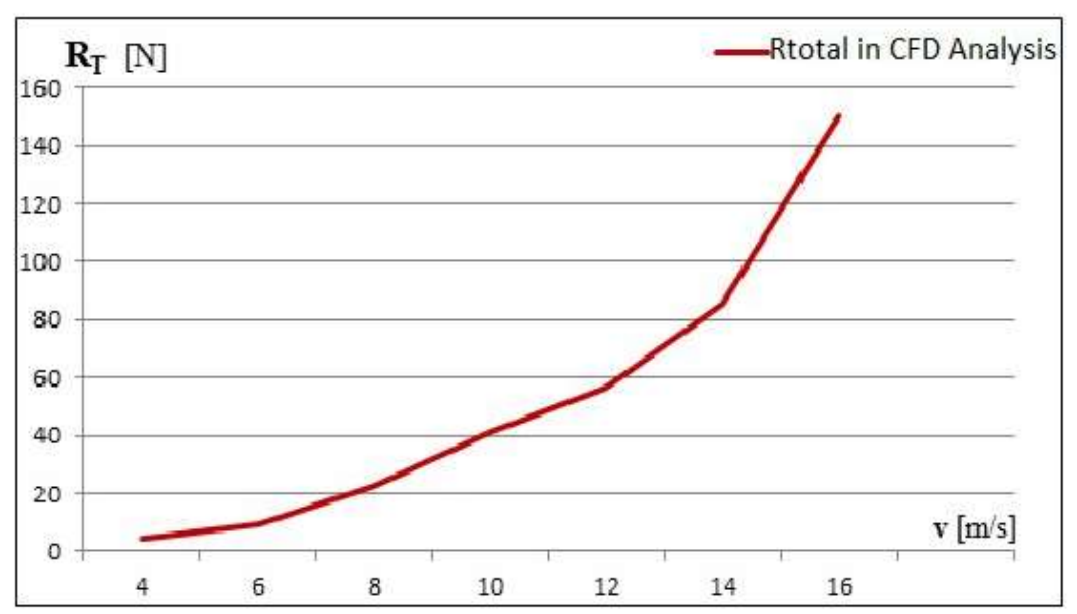

Figure 14. Results of CFD analyses of the model A.P. 


\section{Conclusions and Recommendations}

Many resistance estimation methods have been developed to determine the resistance of ships by making use of the systematic model test results obtained from the past to the present. Thanks to these methods, it is possible to make a general evaluation about the resistance values of a ship or boat. However, it is not possible to perform the towing tank tests of the new generation high tonnage ships under laboratory conditions in a wide speed range optimally, since their model scale values must be chosen very large. In addition, the increase in ship dimensions necessitates the speed of the models to be limited due to both the number of Froude and the limited towing tank length. As an alternative option, choosing the test model scale larger than it should be causes incorrect measurement results due to the scale effect.

In high-speed boats, measurements cannot be performed in the demanded speed range, because the model speeds are very high, and the speed value of the towing vessel cannot reach these high speeds within the desired time interval.

In this study, CFD analyses were carried out for three different ship models and the total resistance values of the models were obtained. Since towing tank test results of the first two models were found, both results were given comparatively. In the third model, since the test results of the ship model A.P. were not available, only the results of the CFD analysis were given in a wide speed range at the diagram.

When the towing tank test results are compared with the ones obtained by the CFD analysis method, it is definitive that they agree with each other. The selection of the appropriate mesh structure and the choosing of the appropriate turbulence model are very important factors in the exact agreement of the CFD analysis results with the physical tank ones.

Generally, it can be thought that the tank test results are more reliable. However, thanks to high performance computing systems, it is inevitable that CFD analyses will produce more realistic results with "numerical laboratories" that do not require turbulence modelling, i.e. by "Direct Numerical Simulation" solvers. Therefore, in the future, significant decreases in design costs are expected in parallel with the decrease in the demand for model tank tests and with shortening of the design time in the preliminary and final design stages of the ships and boats.

\section{References}

[1] ANSYS / FLUENT Tutorial. Chapter 6 - Turbulence Modelling - Introductory FLUENT Training., Retrieved from http://www.petrodanesh.ir/Virtual\%20Education/Mechanics/ANSYS/FLUENT/ (02.03.2019).

[2] Menter, F. (1994). Two-equation eddy-viscosity turbulence models for engineering applications. AIAA Journal, 1598-1605.

[3] Gürsel, K.T., Taner, M. (2019). Hydrodynamic Potential Improvement of Pontoon Boats, Naval Engineers Journal, 131-2, June.

[4] Olivieri, A., Pistani, F., Avanzini, A., Stern, F., Penna, R. (2001). Towing Tank Experiments of Resistance, Sinkage and Trim, Boundary Layer, Wake, and Free Surface Flow around a Naval Combatat INSEAN 2340 Model. IIHR Technical Report No. 421.

[5] Obreja, D., Domnişoru, L., Pãcuraru F. (2006) Integrated System for Data Acquisition and Numerical Analysis of the Ship Resistance Performance in the Towing Tank of Galati University. Romanian Journal of Physics, 53, 137-148. 